\title{
Photocatalysts on Wastewater Treatment and Sustainable Applications
}

\author{
Vicente Rodríguez-González ${ }^{1} \cdot$ Sergio Obregón ${ }^{2} \cdot$ Ana P. Rozo $^{3}$
}

Accepted: 10 December 2020 / Published online: 4 January 2021

(C) The Author(s), under exclusive licence to Springer Science+Business Media, LLC part of Springer Nature 2021

This Special Issue titled "Photocatalysts on wastewater treatment and sustainable applications" represents the theme discussed every 2 years among researchers from around the world who attend the meeting. This time, the 6th Latin-American Congress on Photocatalysis, Photoelectrochemistry and Photobiology $\left(6^{\text {th }}-\mathrm{LACP}^{3}\right)$ was held in Bogotá D.C. Colombia on the campus of the Jorge Tadeo Lozano University in collaboration with the Central University. The 16 articles that appear in this issue were subjected to a rigorous peer-review process carried out with special effort in this Covid-19 outbreak. Different materials synthetized from methodologies such as ball milling, coprecipitation, and so on, yielded photoactive materials for the photocatalytic hydrogen production from water, alcohols degradation, photo-electrocatalytic oxidation of surfactants and dyes, degradation of pharmaceutical pollutants such as ibuprofen and thiabendazole, water disinfection and selective photo-epoxidation of limonene.

All the authors who participated in the meeting and the special issue, feel satisfied by the new collaborations, friendship and knowledge shared during the conference. Keynote speakers, oral lectures and students from different institutions in Canada, Mexico and Colombia are happy with the organizers who open their institutions to promote the scientific spirit that has been growing since 2013, when this series of photocatalytic meetings started.

We are indebted to Prof. Hans-Joachim Freund for this opportunity and we also thank Ms. Gursimaran Kaur and Matthew Smyllie for valuable assistance in the peer review and edit management process.

This meeting is growing worldwide, and the next edition will be at the National Autonomous University of Mexico (UNAM) in Mexico, in September 2021, after the Covid-19 pandemic. Then, the $8^{\text {th }}-\mathrm{LACP}^{3}$ will take place in Toronto, Canada in 2023. We hope that the consolidation of the LACP series will occur in this new time.

Publisher's Note Springer Nature remains neutral with regard to jurisdictional claims in published maps and institutional affiliations.
Vicente Rodríguez-González

vicente.rdz@ipicyt.edu.mx

1 División de Materiales Avanzados, Instituto Potosino de Investigación Científica y Tecnológica (IPICYT), Camino a la Presa San José 2055, Lomas 4a. Sección 78216, San Luis Potosí, México

2 Centro de Investigación en Ciencias Físico Matemáticas, Facultad de Ciencias Físico Matemáticas, Universidad Autónoma de Nuevo León, Av. Universidad S/N, San Nicolás de los Garza 66455, Nuevo León, México

3 Universidad Central, Carrera 5N 21-38, Bogotá, Colombia 